Digital Creativity

\title{
What now, what next-kairotic coding and the unfolding future seized
}

\section{Emma Cocker}

To cite this article: Emma Cocker (2018) What now, what next—kairotic coding and the unfolding future seized, Digital Creativity, 29:1, 82-95, DOI: 10.1080/14626268.2017.1419978

To link to this article: https://doi.org/10.1080/14626268.2017.1419978

曲 Published online: 22 Feb 2018.

Submit your article to this journal 주

Q View related articles $\sqsubset$

View Crossmark data \lceil 


\section{What now, what next-kairotic coding and the unfolding future seized}

\section{Emma Cocker}

School of Art and Design, Nottingham Trent University, Nottingham, UK

\begin{abstract}
Drawing on my experience as a critical interlocutor within the AHRC research projects Live Notation: Transforming Matters of Performance (2012) and Weaving Codes | Coding Weaves (2014-2016), in this article, I propose a conceptual framework for considering the challenges and opportunities for kairotic improvisation within live coding, conceived as an embodied mode of imminent and immanent intervention and invention-in-the-middle, a practice of radical timing and timeliness. Expanding my previous reflections on kairotic coding [Cocker, Emma. (2014). "Live Notation: Reflections on a Kairotic Practice." In Performance Research Journal, on Writing and Digital Media, edited by Jerome Fletcher and Ric Allsopp, 18 (5), 69-76. London: Routledge; Cocker, Emma. (2016). "Performing Thinking in Action: The Meletē of Live Coding." International Journal of Performance Arts and Digital Media 12 (2): 102-116. Cocker, Emma. (2017). "Weaving Codes/Coding Weaves: Penelopean Mêtis and the Weaver-Coder's Kairos." Textile 15 (2): 124-141], in this article, I address the kairotic liveness within live coding's improvisational performance by identifying two seemingly contradictory tendencies within this burgeoning genre. On the one hand, there is a call for improved media technologies enabling greater immediacy of semantic feedback supporting a faster, more fluid-perhaps even virtuoso-approach to improvisation. Alongside, there remains interest within the live coding community for a mode of improvisational performativity that harnesses the unpredictable, the unexpected or as-yet-unknown. Rather than regard these two tendencies in antagonistic relation, my intent is to invite further debate on how the development of intelligent machines might better facilitate improvisatory flow, without eradicating the critical intervals and in-between spaces necessary for creative invention and intervention, without smoothing away the points of technical resistance and intransigence which arguably form a part of live coding's performative texture.
\end{abstract}

\section{KEYWORDS}

Live coding; kairos; thinkingin-action; thought-in-motion; improvisation
In this article, I propose a conceptual framework through which to consider the challenges and opportunities for kairotic improvisation within live coding, conceived as an embodied mode of imminent and immanent intervention and invention-in-the-middle, a practice of radical timing and timeliness. ${ }^{1}$ Whilst the terms kairos, kairotic improvisation and kairotic coding are elaborated and unpacked in more depth as the article unfolds, the definition of kairos adopted draws on its dual meaning, where it is used to refer to both a temporal 'opening'-a cut or 'nick' in time-and a 'willto-invent' capable of responding to this opening

CONTACT Emma Cocker emma.cocker@ntu.ac.uk $\Theta$ School of Art and Design, Nottingham Trent University, Bonington Building, 50 Shakespeare Street, Nottingham NG1 4FQ, UK

(C) 2018 Informa UK Limited, trading as Taylor \& Francis Group 
in the 'living present' (White 1987). Expanding the concept of kairotic coding that I developed in previous research (Cocker 2014, 2016, 2017), within this article my focus shifts to address the kairotic liveness within live coding's improvisational performance by identifying two seemingly contradictory tendencies within this burgeoning genre. On the one hand, there is a call for improved media technologies enabling greater immediacy of semantic feedback, a shift towards predictive coding modelled on previous patterns and habits supporting a faster, more fluid-perhaps even virtuoso-species of programming improvisation. Alongside, there remains interest within the live coding community for a mode of improvisational performativity that harnesses the unpredictable, the unexpected or as-yet-unknown, where performance emerges as a vital site for experimental exploration, the live event of 'thinking-inaction'. 2

My intent is to draw attention to the different futurities within these two approaches: the difference within performance between a technologically predicted 'future' based on what has-been, and the ever-emergent, living instant of the future conceived as 'what now, what next', the 'to-come'. This philosophical reflection on the temporal experience within digital improvisation seeks to foreground the centrality of attending to an expanded sense of the present within live coding, emphasizing the 'flow' of real-time action, the criticality of the moment, alongside both the risk and skillfulness required in engaging with the unknown. Yet, rather than posit technological improvements in antagonistic or oppositional relation to the unpredictable potential of live coding, my aim is to invite further debate on how the development of intelligent machines might better facilitate improvisatory flow, without eradicating the critical intervals and in-between spaces necessary for creative invention and intervention, without smoothing away the points of technical resistance and intransigence which arguably form a part of live coding's performative texture. How might technological innovation increase the potential for inventive forms of improvisatory performance, where a heightened level of collaboration or co-improvisation with machines allows for the emergence of the unexpected, by combining increased performance capacity with a continued embrace of risk and uncertainty, error and failure? Indeed, how might predictive technologies-perhaps counter-intuitively-enable that which cannot be predicted in advance, a truly experimental or surprising mode of improvisation made possible through a more intuitive collaboration between human and non-human?

\section{Live coding's thinking-in-action}

Whilst my article examines the challenges and opportunities for creative interaction between humans and computer systems alongside the scope for improvisational invention therein, my reflections are based on experiences-observations, encounters and conversations-from within two distinct research projects rather than making a general claim about all forms of digital creativity. Specifically, I draw from my experience as a critical interlocutor within two recent live coding-related research projects, Live Notation: Transforming Matters of Performance (2012) and Weaving Codes | Coding Weaves (2014-2016), that in different ways addressed questions related to the liveness of improvisational 'thinking-in-action' at the interface between human and machine, by examining how digital technologies have the capacity to enhance as well as limit the potential for human creativity; to both augment and diminish-activate and inhibit-the development of human dexterity, attention, cognitive agility and tactical intelligence. For Erin Manning and Brian Massumi (2014), this notion of 'thinkings-in-the-act' or 'thought in the act' refers to the immanent movement of thought as it is performed, activated only in-andthrough practice. Here, thinking-in-action could be conceived akin to the immanent 
intensification' of thinking that Alain Badiou $(2005,58)$ (following Nietzsche) asserts is not effectuated anywhere else than where it is given-thought is effective in situ, it is what ... is intensified upon itself, or again, it is the movement of its own intensity'.

Whilst my own interest in 'thinking-inaction' has been explored in-and-through various practice-based artistic research projects, in this article I refer specifically to the practice of live coding, a form of digital improvisation that explicitly foregrounds the real-time character of computational processes. Broadly speaking, live coding describes the improvisatory composition of predominantly computer-generated audio-visual material, where the writing of code itself-or other executable instructions -is presented as a live event for an audience. ${ }^{3}$ Significantly, the writing of code is not just the means for generating audio-visual material, but additionally, this process is often folded into the audio-visual experience itself. Alongside witnessing the coder physically labouring at their laptop, the code itself is also presentedoften projected-live as it is being worked on as a visible part of the performance. Live coding is a revelatory practice intent on the 'showing of the screen', revealing the decision-making and working out within coding, the source code or operational principles as they are being written. As Nick Collins, Alex McLean, Julian Rohrhuber, and Adrian Ward note (2003, 321), live coders 'work with programming languages, building their own custom software, tweaking or writing the programs themselves as they perform'. Live coding is thus characterized by the ability to interact with a running system that is not stopped whilst waiting for new programme statements: the focus is on the writing of code simultaneous to its use. Code is written as it is performed; a practice that is variously referred to as 'coding on the fly', 'just-in-time coding' or else as 'kairotic coding' (Crocker, 2014), an original concept that I proposed for describing the immanent improvisatory quality within certain live coding practices.

\section{Kairotic coding: initial conceptualisation}

My initial conceptualization of the improvisatory nature of kairotic coding emerged as a response to the research project Live Notation: Transforming Matters of Performance (2012), funded by the UK Arts and Humanities Research Council's 'Digital Transformations' theme. Exploring the possibilities of relating live coding (performing with programming languages) and live art (performing with actions), the Live Notation project was led by co-investigators Alex McLean and Hester Reeve working in dialogue with an international network of artists, coders and theorists, including Sam Aaron, Geoff Cox, Yuen Fong Ling, Dave Griffiths, Thor Magnusson, Brigid McLeer, Kate Sicchio, Andre Stitt, Wrongheaded and Maria X, who collectively comprised the Live Notation Unit. On 27 July 2012, I witnessed the Live Notation Unit stage a symposium and series of performances at Arnolfini (an international arts centre and gallery) in Bristol, UK, conceived as an 'experimental laboratory' in which to approach programming as performance art, performance art notation as code, code as speech, bodies as interpreters, involving improvisational sound works (where computer code and the artists' bodies become instruments) and site-specific time-based art works (where notation becomes the 'piece' as opposed to its recording device). McLean and Reeve (2012) conceived the term 'live notation' and principle of live-ness as a means of shared resonance for connecting live art and live coding, asserting that, live notation is an intrinsic part of live work-for both body and code. In this we consider notation as not being something that precedes, defines or is created by a performance, but as activity that resonates within a performance'. The model of 'liveness' within this project privileged the durational, embodied, non-repeatable moment of performance, drawing attention to an improvisatory species of liveness wherein the mode of articulation emerges as a 
live event simultaneous to the unfolding experience, rather than as live re-activation of a preexisting script or score that was rehearsed or planned in advance.

\section{Kairos-will-to-invent}

My assertion is that the improvisatory tendency encountered within the Live Notation project could be conceived as kairotic improvisation, a practice alert to the live circumstances of its own production, capable of creating the conditions for whilst simultaneously responding to the contingencies within its own emergence. Whilst some historical and philosophical contextualisation of the term kairos is required, my intent is not to offer an exhaustive analysis for as Thomas Rickert $(2013,75)$ argues, 'the meaning of the Greek word kairos is itself murky because of its various usages'; its definition shifting, contradictory and therefore lacking direct or exact translation. Indeed, though the temporality of kairos has been conceived in messianic terms as well as to refer to the notion of 'due measure', propriety and decorum, my own reflections draw on the Ancient Greek rhetorical conceptualization where kairos is often taken to mean 'timing' or the 'right time', a 'decisive' critical moment whose fleeting opportunity must be grasped before it passes. Kairos thus describes a qualitatively different mode of time to that of linear or chronological time (chronos): not an abstract measure of time passing but of time ready to be seized, an expression of timeliness, a critical juncture where something could happen. For Eric Charles White (1987, 13), kairos has origins in two different sources: archery, where it describes 'an opening or "opportunity" ... through which the archer's arrow has to pass' and weaving where there is "a "critical time" when the weaver must draw the yarn through a gap that momentarily opens in the warp of the cloth being woven'. Etymologically related to the Greek word keirein-to cut-kairos can be conceived thus as both a temporal 'opening' or critical moment (a 'nick' in time) and, in White's terms, a 'will-to-invent' capable of responding to this opening.

The 'on-the-fly' nature of live coding resonates with White's $(1987,13)$ articulation of kairos as 'adaption to an always mutating situation. Understood as a principle of invention ... kairos therefore counsels thought to act always, as it were, on the spur of the moment'. For White (1987, 13),

Such an activity of invention would renew itself and be transformed from moment to moment as it evolves and adapts itself to newly emergent contexts. The fluid and relative moments of the immediate situation would be constitutively involved in the invention process, which would become an improvisational one.

He asserts that (1987, 54-55) kairos describes an improvisational capacity that is 'contemporary with itself, alert and able to adapt to the present occasion', where 'kairos is offered with the understanding, then, that thought must always be willing, as circumstances change, to being again' (1987, 17). Kairotic improvisation involves letting go of or loosening one's attachment to any preconceived ideas for the unfolding of a performance, surrendering to the contingencies within each new situation. Indeed, whilst some forms of laptop performance (including live coding) might use preexisting or pre-recorded samples that become combined through a process of improvisation during the live event (that are effectively precomposed anterior to the situation and then modified through live performance), live coding provides the capacity for real-time composition including the possibility of 'beginning from scratch' or from the 'blank screen'.

\section{Kairotic futurity}

However, kairotic liveness does not involve the valorization of spontaneity and originality as indicative of authenticity: Philip Auslander (1999) has long since complicated any clear distinction between live and mediated 
performance. Indeed, the live coder might well draw on an existing archive of samples and code threads that have been generated in advance. However, whilst some modes of digital performance would use these components within an already configured structure that accesses the 'has-been' in order to repeat as before, within a kairotic practice the future performance is ever-emergent, ontologically living as much as live. For Maxine Sheets-Johnson (2009) (dance), improvisation is the incarnation of creativity as process. Its future is thus open. Where it will go any moment, what will happen next, no one knows; until the precise moment at which it ends, its integrity as an artwork is uncharted'. The difference in livenesseven aliveness-between kairotic improvisation and forms of performance whose destination is planned in advance could be further elaborated in relation to the different species of temporality and futurity operating therein. Drawing on the philosophical work of Catherine Malabou, Jean-Luc Nancy and Jacques Derrida, JeanPaul Martinon (2007) asks, 'How does one address the coming of the future?' Turning to the French language, Martinon $(2007,1)$ identifies two different words for the future: le futur and l'avenir. The first-le futur-he states, 'refers to something distant or remote, possible, or probable ... Le futur supposes in fact the possibility of projection, predictions, and prophecies'. Whilst le futur is concerned with 'what will or might be', l'avenir, as Martinon $(2007,1)$ notes, is usually translated as ... what is "yet-tocome"'. Though different, both models refer to the future as a linear continuation of time where as Martinon $(2007,15)$ notes, time is 'always one-dimensional and unidirectional; it goes towards the future'. Against this logic, he attempts to reinvent the term futurity by drawing on the radical potential of a third term: $\dot{a}$ venir (the expression of the 'to-come').

For Martinon (2007, 4-5), à-venir 'represents an "unhinging", a 'spacing (and) temporizing' which 'interrupts the present' 'breaking up ...the measurable linearity of space and time'. According to Martinon (2007, 7), 'à-venir surges between the foreseeable, "projectable", "plannable", and programmable future present and the radical future, that is ... that which exceeds or is more than this future possibility'. The concept $\grave{a}$-venir refers to a gap or 'creative interval' between the 'as is' of the present and the 'not yet' of the future; not the 'not yet' of the future conceived as a continuation of the present, but rather that of the 'tocome'. Philosopher Antonio Negri conceptualizes this 'to-come' as the evental 'time for revolution', as kairòs. He describes kairòs as the 'restless' instant where naming and the thing named attain existence (in time), for which he draws example from the way that the poet 'vacillating, fixes the verse' (Negri 2003, 153). For Negri (2003, 152), kairòs describes 'being's act of leaning out over the void of time tocome, i.e. the adventure beyond the edge of time'. Accordingly he argues that, 'Kairòs is the modality of time through which being opens itself, attracted by the void at the limit of time, and it thus decides to fill that void (Negri 2003, 152). Negri $(2003,152)$ conceives the limit experience of kairós as one of 'being on the brink', as 'being on a razor's edge', a point of rupture, of decision. Rather than imagining the future as already existing (that can be predicted in advance), conceptualizations such as à-venir and kairós propose the possibility of a radical future, borne of rupture, discontinuity and of necessary invention.

\section{Invention-in-the-middle: an embodied practice}

Unlike some computer-generated performances that involve the activation of an algorithm conceived in advance and simply let to run its course, within live coding running algorithms have the capacity to be interrupted, rewritten, their course changed. Rather than giving over responsibility to the inevitability of an algorithm's logic, within live coding the performer consciously adopts a medial position, actively 
maintaining the conditions that will keep the unfolding of action dynamic. Debra Hawhee $(2002,18)$ conceptualizes the medial position of 'invention-in-the-middle' as a kairotic movement involving 'simultaneous extending outwards and folding back'; it is a 'space-time which marks the emergence of a pro-visional "subject", one that works on-and is worked on by-the situation'. Here, the opportunity of kairos requires the perceptions and actions of an individual capable of seizing its potential through inventive means. Hawhee $(2004,75)$ argues how a kairotic practice necessitates a sense of 'immanent awareness', 'embodied thought-in-motion' and 'instinctual ... bodily capacity for instantaneous response'. Whilst Hawhee $(2004,67)$ is referring to Ancient rhetoric and athletics, the mode of 'rhythmic, embodied practice' that she articulates seems to correspond with the improvisational modality of live coding. More than a logical or purely conceptual procedure, kairotic coding involves a sense of embodied awareness, where principles of knowing how and knowing when are privileged as much as knowing what. Indeed, the improvisatory practice of live coding does not just involve the logical or rational manipulation of code language; it unfolds as much through a form of kinaesthetic knowledge, the complex embodied relation of rhythm, repetition and response. Maxine Sheets-Johnson $(2009,11)$ uses the term 'kinesthetic memory' to address the question of 'how we do what we do': she draws on Aleksandr Romanovich Luria's terms kinetic melody and kinesthetic melody, to explain how a 'complex sequential activity unfolds ... how muscular innervations and denervations are temporally ordered in the performance of any skilled movement'.

\section{Weaving Codes - thought-in-motion}

Operating as a critical interlocutor within the AHRC research project Weaving Codes | Coding Weaves (2014-2016) provided a context for further exploring the specificity of thinking-in- action whilst improvising within a live running code and how might it relate to the embodied or even kinaesthetic 'thought-in-motion' (Hawhee 2004, 75) activated whilst working on the loom. Led by principle investigators Ellen Harlizius-Klück and Alex McLean, working with collaborative developer Dave Griffiths, Weaving Codes | Coding Weaves involved the radical recuperation of a largely ignored relation between ancient weaving and computational thinking, emphasizing the epistemological connection between these two practices above the habitually foregrounded technical evolution of their respective hardware. Rather than conceive the connection between weaving and coding through the prism of machinic mass-production and its privileged concepts of optimization, efficiency, productivity and standardization, the shared research quest was towards finding a language for describing the interweaving of multiple methods not possible to accommodate within standard mass-production design - techniques involving the complex collaboration and co-operation between human and machine, or that are predicated on the activation of an improvisatory form of embodied knowledge. Ancient loom weaving and live coding both involve a tactile-even tactical-system of physical and cognitive dexterity, the interplay of hand, eye and mind, the cultivation of a processual working knowledge such that it becomes ingrained in mind and muscle, activated at the fingertips, live and emergent to the situation. Indeed, there is an inherent physical, kinetic-even kinaesthetic-dimension to the live writing of code, through the physical engagement with the machine: a sensorimotor movement vocabulary of micro-adjustments, changes and shifts performed in the frantic keystrokes, in the shuttling of the cursor around the screen, in the flash points of activation and execution.

\section{Kairotic improvisation and flow states}

The form of human-computer interaction within live coding foregrounds an active rather 
than passive relation to technology; a more complex, nuanced or even entangled relation, where technology is not so much put to use as worked-with, the process unfolding through attending to-even collaborating with-the resistance exerted by the technology or apparatus rather than conceiving it simply as a tool that needs to be brought under control, mastered. Rather than reducing the role of the human operator, live coding requires heightened levels of dexterity, attention, cognitive agility and tactical intelligence; it is a practice of timing and timeliness, of biding one's time and knowing when to act. Kairos is experienced in-the-midst-of whilst simultaneously felt as out-of-time, the event of kairotic timeliness or ex-temporising operating outside or beyond the temporal frame of chronos. The immanent and embodied thought-in-motion within such an improvisatory practice might be described in terms of 'flow' or 'flow state'. Often conceived as synonymous with 'being in the zone', flow describes a hyper-focused state of 'optimal experience'-or mental state-conceptualized by psychologist Mihály Csíkszentmihályi $(2002,53)$ as 'full absorption', immersion or 'total involvement' in the process of an activity, where the individual stops 'being aware of themselves as separate from the actions they are performing'. Csíkszentmihályi argues that flow states involve an experiential transformation of time, alongside the merging of action and awareness: actions become spontaneous, even automatic-intrinsically rather than extrinsically meaningful. Here, Csíkszentmihályi $(2002,69)$ states, 'Life is justified in the present, instead of being held hostage to a hypothetical future gain'. Indeed, live codinglike many other improvisatory practicesinvolves states of heightened concentration and temporal disorientation, where an intrinsic value is placed on the process in-and-of-itself.

For Csíkszentmihályi $(2002,64)$, flow is also characterized by loss of self-consciousness. However, this does not mean that the individual remains unaware of his or her actions; rather, it enables an expansion of attention beyond the 'boundaries of our being', which as Csíkszentmihályi $(2002,64)$ claims is 'based on a concrete experience of close interaction with some Other, an interaction that produces a rare sense of unity with these usually foreign entities'. It is perhaps in this sense, that the live coder 'collaborates' with his or her technology through a process of interaction in a 'system of action' that is greater than the intentions of the individual self, that involves letting go of self-conscious control whilst maintaining a heightened sense of mental activity and the activation of one's skill commensurate to the challenge. Indeed, Csíkszentmihályi (2002, 54) argues that although 'flow experience appears to be effortless, it is far from being so. It often requires strenuous physical exertion or highly disciplined mental activity. It does not happen without the application of skilled performance. Any lapse in concentration will erase it'. Accordingly, the optimal experience of flow depends on achieving the 'sweet spot' of desirable difficulty between the nature of the challenge and one's available skill, between one's intention and capacity. Echoing many of the characteristics identified within Csíkszentmihályi's articulation of flow, Sheets-Johnson asserts that (dance), improvisation is process through and through, a form which lives and breathes only in the moving flow of its creation, a flow experienced as an ongoing present [...] to create an unbroken now [...] an ongoing flow of movement from an ever-changing kinetic world of possibilities'. She states that (2009, 29), improvisation is 'either in the process of being created-in the very process of being born-or it is not at all'. However, for SheetsJohnson $(2009,35)$, the 'way of being in the world' within thinking in movement is 'not the work of a symbol-making body, a body mediating its way through the world by means of a language'. Yet, the improvisatory nature of live coding is exactly 'by means of a language': it is a form of improvisation predicated on the live writing of code; moreover, 
activated in-and-through the mediation of technology.

\section{Improvisation through mediation}

So how might the numerical-linguistic-symbolic mediation operating within live coding impact on its potential for improvisatory states of embodied, kairotic flow? Indeed, for Hawhee $(2004,70)$ 'kairotic impulses' 'are not limited to a seat of reason or conscious adherence to a set of precepts' but rather, the bodily capacity for instinctive response can be habituated, such that they become intuitive. Herein too, live coding deviates from the ancient kairotic practices, since its unfolding processes are non-intuitive, even counter-intuitive. In coding, there is often no intuitive relation between action and result: the subtlest modifications within the process-small changes to the code thread-have the capacity to affect unexpected change. Indeed, in changing the programme as it is running there is an inherent risk of failure, where small typing errors can result in the production of code that is unable to execute at all. For Csíkszentmihályi $(2002,56)$, to achieve a state of flow there should be a focused sense of intention: he states that even where a clear sense of 'goal' or outcome has not been 'set in advance', one should still be able to gauge 'Yes, this works; no, this doesn't'. However, in order to activate these micro-decisions from 'in the zone' of flow it is necessary to receive 'immediate feedback'.

Herein, lies one further challenge for the improvisatory live coder, for whilst live coding is described as a mode of real-time composition, in reality, there is a lag-due to technical latency -between the writing of code and its execution. There is an inescapable delay in the feedback loop between action (writing of code) and the effects of code's activation. Feedback is nonimmediate such that within the live and present moment, the live coder is both attending to the unfolding of their live performance (based on their coding actions from moment's past) whilst also setting up the conditions for what will come next. The coder's attention is split between the present-of-the-present moment (the as is) and a 'future-of-the-present moment' (the yet-to-come). This lag further complicates the issue of the liveness within live coding: unlike other forms of live composition, the relationship between a performer's actions and the resulting effects is asynchronous. Or rather, there are parallel threads of arrhythmic liveness: the live (yet arguably no longer live) unfolding of the effects generated through the event of coding, and the live event of coding writing itself, both of which are simultaneously experienced by coder-performer and audience.

\section{Immediacy and timeliness of feedback: levels of liveness}

Whilst the temporal nature of kairotic improvisation might be imagined in terms of its swiftness and immediacy, its capacity for quick response, the practice of live coding must navigate this temporal lag between a decision and its effects. One issue for digital-human improvisation within this field of practice could be to explore how digital technologies and the development of 'intelligent' machines might better enable the improvisatory state of kairotic 'flow'? One response to the 'problem' of technical latency is a call for improved media technologies enabling greater immediacy or 'timeliness' of execution feedback, alongside reducing the scope for error, effectively making the performance more 'real-time', increasing the perception of its 'liveness'. For Steven Tanimoto (2013), 'liveness' involves 'minimizing the latency between a programming action and seeing its effect on program execution'; it is a question of 'the temporal relationships between programmer actions and computer responses'. Tanimoto (1990) developed a hierarchical system initially for describing the four different degrees of liveness within programming: Level 1 (Informative): No semantic feedback about a program is provided-he argues that this first 
level involves the four separate phases: edit, compile, link and run. In liveness level 2 (Informative and Significant), semantic feedback is available on demand on a selected component, 'the programmer would do something, would ask for a response, and some time later, the computer would respond' (Tanimoto 2013). In level 3 (Informative, Significant and Responsive), incremental semantic feedback is automatically provided with an incremental programme edit: 'the computer would wait and sometime after the programmer did something, would respond' (Tanimoto 2013). In level 4 (Informative, Significant, Responsive, and Live), incremental semantic feedback is automatically provided for other data events such as mouse clicks or exceptions, 'the computer wouldn't wait but would keep running the program, modifying the behavior as specified by the programmer as soon as changes were made' (Tanimoto 2013).

\section{Towards greater improvisation or efficiency?}

Tanimoto has since elaborated two further levels of liveness, which in addition to swifter feedback response involve tactical and strategic prediction. Made feasible through the use of machine learning technology, statistical analysis of programmer behaviour and 'logical reasoning about meaningful choices', Tanimoto argues that in the new liveness level 5 (Tactically Predictive), 'the computer not only runs the program and responds, but also predicts the next programmer action [...] Instead of the environment lagging behind, or just keeping up with the programmer, it stays a step ahead of the programmer' (Tanimoto 2013). Level 6 would involve further 'intelligent inference of the programmer's intentions or desires' (Tanimoto 2013). For Tanimoto (2013), the intelligence required to make such predictions into the system is an incorporation of one kind of agencythe ability to act autonomously. Agency is commonly associated with life and liveness. One might argue that here, liveness has spread from the coding process to the tool itself. In one sense, these technical developments promise towards improved human-machine interfaces and improvisation, with predictive coding (modelled on previous habits) supported by faster response and processing times seemingly maximizing the potential for kairotic flow, for increased spontaneity, for more immediate coding 'on the fly'. Rather than a passive 'tool', the computer is afforded a degree of decision-making responsibility, based on its capacity to 'second guess', pre-empt or predict the next step within a creative flow of action as it 'learns' more about a performer's preferences and tendencies.

Certainly, improvements in semantic feedback and the development of tactical prediction and auto-completion could enable greater possibilities for improvising 'in the moment' or 'in the zone'. However, such technological advances might not necessarily give rise to inventive forms of improvisatory liveness conceived as a mode of live thinking-in-action, of real invention and intervention. Indeed, the 'pressure to perform'-even entertain-within certain live coding performance contexts places high demands on the performer. Under these conditions, technical developments might serve the betterment or perfection of a performance; that is, become instrumentalized at the service of technical virtuosity, through reducing the potential for error alongside increasing the performer's capacity for repetition of complex sequences of coding. Here, the intrinsic motivation associated with flow states (heightened value on the process and its challenges), gives way to a form of extrinsic motivation dependent on external factors including the 'success' of the performance 'product', which arguably in turn becomes measured according to the normative criteria set within our contemporary neoliberal culture of acceleration and immediacy: the eradication of error and delay in favour of more easily attainable complexity and precision, speed and efficiency, productivity and 
repeatability. Moreover, what might become cultivated is a reliance on predictive options, on a received standard or model developed for a specific (predetermined) purpose or function. The possibility of deviation from the norm, for bespoke options, for modification or adaptation becomes increasingly less of an option. Speed and immediacy become mistaken for liveness; increased efficiency leads to less waste, which in turn can result in less risk. Indeed, rather than measuring the success of human-computer improvisation based on how effectively technologies facilitate the process of 'creative flow', the collaborative potential of improvising with computers might also recognize the critical value-even a different sense of computer agency-within those moments of intransigence and resistance.

\section{Avoiding the predictive becoming predictable}

Since tactical prediction is based on a model of statistical likelihood that differentiates between the 'least likely' and 'most likely', how does one resist the normatization and narrowing of options within this model? How does one shift from 'what is' or 'has been' to the potential of 'what if, 'what else' or even 'what might be'? Predictive technologies offer a form of digital personalization based on existing patterns and tendencies, but how does something new or unexpected emerge within a predictive system? How does one resist simply repeating the already known? How does one avoid the predictive becoming predictable? Indeed, as White (1987, 17-18) asserts, the impulse to repeat, which ratifies the comfortable notion that knowledge is in principle finite, encourages us to speak not to the present occasion (the locus of genuine novelty) but from (in imitation of) the purely ideal constructs of our memories'. A kairotic practice involves responding to each situation anew, rather than based on responses that are already rehearsed and ready in waiting. Kairos is a contingent form of working knowledge, not based on knowing how to deal with a situation in advance, where the future is predicted and prepared for. It is a form of knowledge borne of the moment, from having confidence that the right decision will be made when required: it involves trusting (tô $i$ kairôi-'to trust the moment' [Hawhee 2002, 18]) that a response will be performed appropriately and with skill at the propitious time. As Hawhee states, ' $(t)$ he fleeting movement of kairos necessitates a move away from a privileging of "design" or preformulated principles' (2004, 78), towards an emphasis on the 'body, timing, and a flexible, responsive intelligence' (193).

One argument could be to assert that technological prediction reduces the need for 'embodied confidence', limiting the range of choice to a pre-set menu of options conceived in advance. However, since there are always a finite number of possibilities for any coding statement, the human performer is already operating within given parameters. Moreover, the human performer might all too quickly return to a familiar coding repertoire within the pressured context of live improvisation. Alternatively, computer prediction does not have to privilege the 'most likely' option, and could instead be used tactically for actively circumventing the problem of 'being predictable'. The intent then is not to suggest that intelligent machines increase predictability, but rather to put pressure on the human performer's capacity and receptivity for seizing the new opportunities made available through technological developments. Indeed, whilst an embodied, kairotic facility is developed through rhythmic, repeated acts of habituation, as Glyn P. Norton $(2016,268)$ asserts, this is 'not about allegiance to ingrained habits, but rather about our readiness to repudiate the habitual, to break with routine-to improvise'. In these terms, the capacity for randomness made possible through working with computers creates an unpredictable field of contingency, forcing the human performer to 'repudiate the habitual', 'to trust 
the moment'. Here, predictive technologies might not always be deployed in the service of more fluid even virtuoso-performance, but instead, as with some modes of human collaboration, serve to thwart familiar ways of working by willfully avoiding the 'most likely' choices, creating the working conditions for the new and unexpected.

\section{Biding one's time: the critical of the interval}

Alternatively, rather than view the lag or latency within coding as a problem or deficiency needing to be reduced or resolved, is it possible to conceive of critical potential within these interruptive intervals? Indeed, it is tempting to focus on the 'just-in-time' nature of live coding's improvisational decision-making as one that is necessarily connected to speed of thought urgent in the now of the present as it is seized. However, the performativity of timing and timeliness within kairos is not performed in haste, but also relies on the dual principles of slowness and speed. ${ }^{5}$ Paradoxically perhaps, the critical opportunity within the 'opening' of kairos (ready to be seized) might only be discerned through a slowing down of habitual flows and rhythms, thereby producing the necessary quality of 'attention'. Referring to the work of Henri Bergson, Simon O’Sullivan $(2006,45)$ argues that 'attention' involves 'the suspension of normal motor activity which in itself allows other "planes" of reality to become perceivable (this is an opening up to the world beyond utilitarian interests). The event then emerges from the world but from a world usually imperceptible'. Moreover, as O’Sullivan $(2006,37)$ states, it is this "affective-gap", or "hesitancy" as Henri Bergson understood it, between stimulus and response, which in itself allows creativity to arise'.

Indeed, for some thinkers, the loss or eradication of thresholds and intervals results in the impoverishment of lived experience. According to Byung-Chul Han (2017, 37),
'The totalization of Here and Now divests the in-between spaces of any meaning. Today's experience is characterized by the fact that it is very poor in transitions'. Advocating a critical value for the interval he asserts that, 'The time between departure and arrival is an uncertain time during which we must reckon with the incalculable. But it is also a time of hope or expectation, which prepares the arrival' (Han $2017,37)$. What might become lost in the eradication of technical latency, in the quest for a speedier arrival at the intended 'result'? Indeed, for Han (2017, 37-38),

If the goal is the sole point of orientation, then the spatial interval to be crossed before reaching it is simply an obstacle to be overcome as quickly as possible... Acceleration is the attempt to make the temporal interval that is needed for bridging the spatial interval disappear altogether... Acceleration leads to a semantic impoverishment of the world.

Han $(2017,38)$ specifically notes how 'technological possibilities for recurrence destroy the temporal interval which is responsible for forgetting. They make what is past instantaneously retrievable and available. Nothing must evade this instantaneous access'. Conceived in these terms, tactical prediction could be viewed as an attempt to 'destroy the temporal interval' at the same time diminish the likelihood of forgetting. For Han, against the eradication of intervals that creates a paradoxical present with no duration, he argues a need for in-between times, for the time of waiting, since intervals not only delay but also allow us to linger.

Indeed, lag is not only technological, since as Brian Massumi $(2015,91)$ notes, it has been verified that there is a delay, an 'infra-instant' 'interval of perception' (of a half-second) between 'the brain activity initiating a movement and the conscious registering of the "decision to act"'. In one sense, live coding actively makes visible the interval-as an active, expectant space wherein the working decisions or working out is shown prior to its execution. 
The gap or delay between witnessing the generation of code and encountering its effects holds certain dramatic tension even. Live coding shows the deliberation as something is being worked on, those threshold moments before the decision to act or intervene, those indeterminate spaces of doubt or hesitation, the movement of thought and fingers between this or that option, between the yes and the no. It shows the time that thinking-in-action takes. Moreover, intervals leave space for listening, for the response based on receptivity to the very contingency of the situation. Against the privileging of accelerated real-time performance-and narrowing of the feedback loop between coding and its execution through technological advancement-can the gaps and lags within improvisational live coding be conceived as kairotic intervals or even openings for biding one's time and for deciding when to act?

\section{On not knowing: courting the unexpected}

The improvisatory nature of live coding involves creating the germinal conditions wherein something unplanned for or unanticipated might arise, something unknown or serendipitous. It involves the cultivation of a contingent form of present-activated futureoriented imagination intent on courting rather than thwarting the unexpected. Indeed, the very principle of improvisation-of beginning a performance without pre-set plan or script, without knowing where it will lead-necessarily embraces a sense of risk and uncertainty, the stepping off or away from what is known towards 'not knowing'. The challenge then is one of leaning towards rather than away from the void of the not-yet-known; moreover, to resist 'filling' that void too hastily with a repertoire of predicted forms and practised rhythms. Rather than striving to successfully execute an already known and rehearsed 'script' (the repetition or revisitation of what already exists), the criticality of live coding's improvisational performance could be conceived in relation to the possibility therein for encountering something new; in the challenge, provocation and even pleasure of the unexpected, the unpredicted and unpredictable. Instead of smoothing away the potential of risk, error or even failure through technological development, emphasis might instead be directed towards the creative seizing of opportunity, accident, chance and contingency within the liveness of humancomputer interaction. Indeed, whilst Csikszentmihalyi's flow state does involve some sense of control, he conceives this as the 'paradox of control', since it is based on the 'possibility, rather than the actuality, of control', or rather 'not the sense of being in control, but the sense of exercising control in difficult situations' $(2002,61)$. In these terms, the desire for risk and uncertainty within an improvisatory context do not reflect the 'pathological thrill that comes from courting disaster' (Csíkszentmihályi 2002, 61), nor the craving for danger in-andof-itself, but rather for the active challenge of working with the contingent situation such that an unexpected outcome is produced.

For many live coders, collaboration itself emerges as a practice less for the pooling of skills and resources, as a means for increasing interruption, interference and chance encounters, the contingencies within co-production or co-emergence willfully thwarting the possibility of solo virtuosity. Can collaboration between human coder and intelligent machine be conceived in such terms, as a mode of improvisatory working with computers that-akin to working with other humans-harnesses the points of resistance and intransigence as productive constraints, as desirable leverage against which to work? Rather than simply an intelligent tool (or even mindless tool box) that is put to work by the coder-performer in the service of better performance, how might improved media and deep learning technologies allow for heightened forms of co-improvisation 
that actively play with the capacities and resistances of both performer and computational system? Can technological improvementsresulting in higher levels of computational liveness-be swerved from the teleology of increased efficiency, productivity and repeatability, alongside the limitation of error, to become truly tested within the context of coding performances that are playfully experimental, that retain the potential of the unpredictable or the unknown? I began the article by identifying two tendencies observed within the burgeoning genre of live coding: the call for greater immediacy of semantic feedback supporting a faster, more fluid approach to improvisation, alongside an interest in a form of improvisational performativity that harnesses the unpredictable, the unexpected or as-yetunknown. Certainly, these tendencies could be conceived as oppositional, however, to do so would be to miss the opportunity-the kairos even-for imagining their complementarity, for developing new forms of human-computer improvisation that creatively and critically test their entanglement.

\section{Notes}

1. This article has been shaped by ideas emerging through collaborative discussion with Alan Blackwell, Geoff Cox, Alex McLean and Thor Magnusson as part of the publishing project Live Coding: A Users Guide, and informed by a series interviews that I conducted with Sam Aaron, Benoit and the Mandelbrots, Shelly Knotts and Alex McLean as part of the research for this project. I am very grateful for the reviewers' comments that prompted a more nuanced line of exploration within this article.

2. See Emma Cocker (2016) for more on the relation of 'thinking-in-action' to live coding.

3. See International Journal of Performance Arts and Digital Media, Live Coding 12 (2), 2016, eds. Thor Magnusson and Kate Sicchio.

4. See also Luria (1973).

5. See also Tom Hall's Slow Code Manifesto, http://ludions.com/texts/2007a/.

\section{Disclosure statement}

No potential conflict of interest was reported by the author.

\section{Notes on contributors}

Emma Cocker is a writer-artist based in Sheffield, UK and Associate Professor in Fine Art at Nottingham Trent University. Her recent writing has been published in Failure, 2010; Stillness in a Mobile World, 2010; Drawing a Hypothesis: Figures of Thought, 2011; Hyperdrawing: Beyond the Lines of Contemporary Art, 2012; Reading/Feeling, 2013; On Not Knowing: How Artists Think, 2013; Choreographic Figures: Deviations from the Line, 2017; The Creative Critic: Writing as/about Practice, 2018, and as a solo collection entitled The Yes of the No, 2016.

\section{ORCID}

Emma Cocker (1) http://orcid.org/0000-0002-29857839

\section{References}

Auslander, Philip. 1999. Liveness: Performance in a Mediatized Culture. London: Routledge.

Badiou, Alain. 2005. Handbook of Inaesthetics. Translated by Alberto Toscano. Stanford, CA: Stanford University Press.

Cocker, Emma. 2014. "Live Notation: Reflections on a Kairotic Practice." In Performance Research Journal, on Writing and Digital Media, edited by Jerome Fletcher and Ric Allsopp, 18 (5), 69-76. London: Routledge.

Cocker, Emma. 2016. "Performing Thinking in Action: The Meletē of Live Coding." International Journal of Performance Arts and Digital Media 12 (2): 102-116.

Cocker, Emma. 2017. "Weaving Codes/Coding Weaves: Penelopean Mêtis and the WeaverCoder's Kairos." Textile 15 (2): 124-141.

Collins, Nick, Alex McLean, Julian Rohrhuber, and Adrian Ward. 2003. "Live Coding Techniques for Laptop Performance." Organised Sound 8 (3): $321-330$.

Csíkszentmihályi, Mihaly. 2002. Flow: The Classic Work on How to Achieve Happiness. London: Rider. 
Han, Byung-Chul. 2017. The Scent of Time. Cambridge: Polity Press.

Hawhee, Debra. 2002. "Kairotic Encounters." In Perspectives on Rhetorical Invention, edited by Janet Atwill and Janice M. Lauer, 16-35. Knoxville: University of Tennessee Press.

Hawhee, Debra. 2004. Bodily Arts: Rhetoric and Athletics in Ancient Greece. Austin: University of Texas Press.

Luria, Aleksandr Romanovich. 1973. The Working Brain. Translated by Basil Haigh. Harmondsworth: Penguin Books.

Manning, Erin, and Brian Massumi. 2014. Thought in the Act: Passages in the Ecology of Experience. Minneapolis: University of Minnesota Press.

Martinon, Jean-Paul. 2007. On Futurity: Malbou, Nancy and Derrida. Basingstoke: Palgrave Macmillan.

Massumi, Brian. 2015. "The Crannies of the Present." In Performance and Temporalisation: Time Happens, edited by Stuart Grant, Jodie McNeilly, and Maeva Veerapen, 91-100. Basingstoke: Palgrave Macmillan.

McLean, Alex, and Hester Reeve. 2012. "Live Notation: Acoustic Resonance?" International Computer Music Conference (ICMC). http://hdl. handle.net/2027/spo.bbp2372.2012.012.
Negri, Antonio. 2003. Time for Revolution. New York: Continuum.

Norton, Glyn P. 2016. "Time, Improvisation and Opportunity." In The Oxford Handbook of Critical Improvisation Studies. Vol. 1, edited by George E. Lewis, and Benjamin Piekut, 262-288. Oxford: Oxford University Press.

O'Sullivan, Simon. 2006. Art Encounters Deleuze and Guattari: Thoughts Beyond Representation. Basingstoke: Palgrave Macmillan.

Rickert, Thomas. 2013. Ambient Rhetoric: The Attunements of Rhetorical Being. Pittsburgh: University of Pittsburgh Press.

Sheets-Johnson, Maxine. 2009. The Corporeal Turn: An Interdisciplinary Reader. Exeter: Imprint Academic.

Tanimoto, Steven. 1990. "VIVA: A visual language for image processing." Journal of Visual Languages \& Computing 1 (2): 127-139.

Tanimoto, Steven. 2013. "A Perspective on the Evolution of Live Programming." In LIVE '13 Proceedings of the 1st International Workshop on Live Programming, 31-34. https:// liveprogramming.github.io/2013/papers/liveness. pdf.

White, Eric Charles. 1987. Kaironomia: On the Will to Invent. Ithaca, NY: Cornell University Press. 